copy I have received, and also that the "May, 1875 " has a line drawn through it. While on the subject let me add that the Zoological Society itself, in its "Transactions," sets a bad example in this respect. Each paper bears a date at the foot of its first page, but the date is likely to be misleading in years to come, for it is that of the printing off the sheet-an essentially private matter, with which the public has nothing to do-and not that of the publication.

Another F. Z. S.

\section{Meteor Observations}

A BRIEF summary of the August (Perseid) meteor observa. tions at York may be of interest.

Watch was kept on the Ioth, IIth, I2th, and I4th. The night of the I Ith was very hazy, the rights before the roth cloudy. There was also much moonlight, except on the 14th. Yet, after making all due allowances, Prof. Herschel thinks that this year's shower indicates a minimum; the last decided minimum being in 1862 .

The hourly number on the four nights mentioned were, for one observer, $22,8,12,15$, respectively. Perseid radiant and sub-radiants gave $18,6,9,7$. Thus, as the shower progressed, there was a regular decrease in the number of Perseids. The apparent exception of the Ioth was due to the haze. Prof. Herschel gives I5-20 as the hourly number in Kent. On the I4th half the Perseids came from Mr. Greg's sub-radiant at $\gamma$ Cassiopeix.

In the south large meteors appear to have been scarce. Here eight, brighter than ist mag. stars, were seen. One, a bolide, low down in the N.W. was very fine. A meteor in the south-west, brighter than Jupiter, was observed by Mr. Waller at Birmingham as a very brilliant object.

The total number observed at York was 105, and 90 of these were mapped. Of the latter 66 were Perseids, 43 with trains. On the roth five other radiants produced eight meteors out of 53; viz., Cygnus, three; Pegasus, two; Polaris, one; Draco (Hercules), one ; and Ursa Major, one. Fifteen meteors on this night were as bright, or brighter, than a I mag. star. Only two of $4_{\text {th }}$ mast. brightness were seen, in consequence of the moonlight.

Of meteors stationary, or nearly so, three were mapped:-A Perseid on the $\mathrm{r} 2 \mathrm{th}$ at $\mathcal{R} 32 \frac{1}{2}$ and $\delta+58 \frac{3}{2}$, its train lasting $2 \frac{1}{2}$ secs. ; on the r 4 th a Cygneid at $\mathbb{R} 306^{\circ} \delta+35^{\circ}$, and an unknown radiant, probably near 5 Vulpecula, gave the third at $\mathbb{R}$ $295^{\circ} \delta+28$.

Three meteors unmistakably confirm Mr. Greg's sub-Perseid radiant by $\gamma$ Cassiopeiæ, whilst several others probably radiate from the same. The radiant, Greg 83 , by $\eta$ Draconis, gave two meteors on the 12 th and one on the I4th. It is put down, however, as lasting only from July $12-3 \mathrm{I}$.

Six Perseids on the roth, and four on other nights, seem pretty clearly to indicate a sub-radiant at $\mathbb{R} 50^{\circ}, \delta+40^{\circ}$, near a Persei. The rest, as Prof. Herschel also noticed, shot very constantly from the chief radiant, between $\eta$ and $\chi$ Persei. Here, however, $\eta$ Persei seemed the most central point.

York, Aug. 15

\section{J. Edmund Clark}

\section{THE FRENCH ASSOCIATION}

$\mathrm{IN}$ addition to the notes already given with regard to the forthcoming meeting of the French Association at Clermont, the following particulars relating to the Puyde-Dome (furnished by our correspondent there) will doubtless be found interesting :-

\section{Clernont, August I3}

The Puy-de-Dôme is connected with most important scientific events, which render it notable amongst more lofty mountains.

Pascal, in 1644 , then quite a young man, was apprised by Pere Mersenne, the celebrated friend of Descartes, that Torricelli had invented his tube. The then admitted explanation was that nature abhorred a vacuum.

He entered into a correspondence on the subject with Father Noel, a Jesuit professor of natural philosophy in the College of Clermont. Father Noel contended against the very existence of the vacuum, and asserted that the so-called vacuum was filled by luminous matter entering through the glass. Pascal answered by arguments worthy of his genius, and to be recommended for consideration in the discussion about radiometers. He said,
"As the nature of light is known to neither you nor $m e$, and as it is very likely it will always be so, $I$ see it will be long before your reasoning acquires the force which is necessary to its becoming the source of any conviction." After having uttered this opinion he reflected more fully upon the subject, and was led to believe that the surplus height of mercury in the tube was equivalent to the weight of the air which could not reach the molecules, being intercepted by the resistance of the glass. This led him to inquire if air-pres. sure was not lessened by taking the Torricellian tube to the top of a mountain, The experiment was made in Paris first on the top of St. Jacques la Boucherie Tower and Notre Dame. As the difference was found to be only a few lines, Pascal sent his brother-in-law, Perrier, who was a counsellor in the Cour-des-Aules at Clermont, to the top of Puy-de-Dôme with a Torricellian tube. Clermont was supposed to be at an altitude greater than Paris by 400 toises; Font-de-l'Arbre is a village in the vicinity of the mountains where carriages are obliged to stop, at 250 toises from Clermont, and 250 toises from the top of the mountain. All these measurements are incorrect ; a toise being I' 94 metres, we find the following differences:- Paris, 60 metres, Clermont, 407 ; difference, 347 metres, instead of 776 , as assumed by Pascal; Puy-de-Dôme, I,465. Difference between Puy and Clermont $=1,058$ metres ; according to Pascal only 952 metres.

The loss of mercury from Couvent des Minimes to the top of Puy was found to be $37 \frac{1}{2}$ lines ; at Font-de-l'Arbre a diminution of $14 \frac{1}{2}$ lines from Minimes. A line is equal to $2 \frac{1}{4} \mathrm{~mm}$

Perrier discovered no difference, owing to the wind or state of the atmosphere. Such was not the opinion of Pascal, who discovered that the mercury varies according to the atmospheric conditions of the air. But Perrier was only an amateur experimentalist, and his special ideas had little weight with his clever brother-in-law.

In order to ascertain the fact, continuous abservations were made at Clermont, by Perrier, during the years I649, I650, and I65I. They were simuitaneously made at Paris and at Stockholm, where Descartes was then living at the court of the famous Queen of Sweden. They were continued by Descartes up to the time of his demise.

It is strange that the Pascal experiments were made the very year when Torricelli died, and the results published only in I664, two years after Pascal's death.

\section{THE SCIENCE DEGREES OF THE UTN- VERSITY OF LONDON}

WE have received from the Registrar of the University of London a copy of the Report of a Committee, and the new regulations which have been introduced in harmony with that Report, in the examinations for the science degrees. From a perusal of the Report, which we subjoin, all will feel how much is gained by the prompt action of the Senate of the University in so speedily modifying the plan of their examinations in accordance with the experience which they have obtained during the last seventeen years. It is not however, only experience in the examination of science students which has led to the necessity for change, but the stimulus which has been given to the teaching of physics and biology, by the founding of science degrees and otherwise, has so altered the method of teaching these subjects that what was expected to be known formerly is quite different from that taught by the most able exponents of the subjects at the present time.

No change has been made in the Examination for the Doctor of Science degree, which we regret, because in the Report of the Duke of Devonshire's Committee on Scientific Education great stress was laid on the importance of obtaining an original thesis from each candidate.

The Report of the Committee runs as follows:- 
"In accordance with the reference made to them by the Senate (Minute I28, May 13, I874), the Committee, after having revised the regulations relating to the Degree of Bachelor of Arts, have given a long and serious consideration to those relating to the Degree of Bachelor of Science. It will be remembered that when those regulations were first framed in the year 1859 , no guidance was afforded by previcus experience, the degrees in science instituted by this University being the first of their kind in the United Kingdom. The Committee by which they were drawn up desired to encourage science students, who might intend to devote themselves to some particular department of science as the pursuit of their lives, to base their special study upon a broad foundation of scientific knowledge; and while the regulations for the Doctorate were framed in such a manner as to permit a high degree of specialisation, the regulations for the Bachelor's Degree were designed to secure the possession of such general culture as should be likely to prevent its holder from becoming a mere specialist.

"Eighteen years' experience of the working of these regulations, however, has made it obvious that the present system is not well adapted to the requirements of scientific education as now conducted. Almost every department of science has undergone a higher development, so as to render it more difficult for a student to obtain an aclequate mastery of its fundamental principles and conceptions. Again, it has come to be generally felt that scientific knowledge, to be real, must be practical, as well as theoretical ; and that a thorough knowledge limited to a comparatively small range, is preferable to a slighter acquaintance spread over a more extended area. And it is the general experience of teachers, that there is from the commencement of their academical course such a decided preference on the part of nearly all students of scince for either the physical or the biological group of subjects, that the attention of each student is given to one group almost to the exclusion of the other. It was further urged that the hiatus is too wide between the almost elementary knowledge of the several departments of science required in the Bachelor's Examination, and the very high attainment in some limited department which is required as the qualification for the Doctorate; and that it would be extremely desirable that this hiatus should be narrowed, by limiting the number of subjects to be brought up by candidates for the B.Sc. Degree, and proportionally raising the standard of proficiency required.

"Several of the ablest teachers in institutions connected with the University, and of its most experienced examiners (past and present), concurred, therefore, in recommending to the Committee, that, keeping the First B.Sc. Examination nearly as it is, an optional divarication should be aliowed at the Second between the mathematico-physical and the biological subjects; and the Committee, feeling satisfied that such a limitation would be advantageous, proceeded to carry it out, by framing (with the assistance of their examiners and other distinguished men of science) new programmes in the several departments of study, that should suit what are now felt to be their respective requirements. But when these new programmes (in which, wherever feasible, practical were combined with written examinations) were put together, the çonclusion was forced on the Committee, that, even when the whole aggregate of subjects it was deemed right to include was divided into two groups, the acquirement of the proficiency expected in the several subjects thus grouped, would be a task too severe for the average capacities of science students. And after much consideration and communication with their scientific advisers, the Committee have arrived at the conclusion that it would be desirable rather to diminish the number of subjects which each candidate should be required to bring up at the Second B.Sc. Examination, than to exact anything short of the "competent knowledge" of each subject for which these programmes provide. They are further of opinion that each candidate, instead of being required to include either the whole or a part of the subjects he selects in one or other of the before-mentioned groups, should be allowed a free option among all of them, so as to combine them in any way that may best suit his taste and ulterior objects-thus leading him onwards to the still higher specialisation of the Doctorate.

"Acting on this principle, the Committee have framed a new set of regulations for the Degree of Bachelor of Science, which they now submit to the consideration of the Senate. In the First Examination, which every candidate will be required to pass, while the programmes in mathematics, experimental physics, and inorganic chemistry have been carefully revised, little fundamental change has been made in them. In place of the superficial acquaintance with both Zoology and Botany formerly required at this examination, the Committee now recommend a single examination (written and practical) in General Biology; in which a more thorough knowledge shall be required of the simplest forms and elementary phenomena of animal and vegetable life, such as is now made the basis of the teaching of some of the most distinguished professors in each department. Thus the student who may be intending to devote himself specially to physical or chemical science, will be brought to apprehend the general conceptions common to the two great organic kingdoms, without being required to master the specialities of either. And the student who intends to present himself at the Second B.Sc. Examination in either physiology, zoology, or botany, or all combined, will have laid the best foundation for those special studies in the study of general biology.

"The regulations for the Second B.Sc. Examination, on the other hand, are framed with the view of allowing the candidate to bring up any three of the following nine subjects :-

I. Pure Mathematics.

2. Mixed Mathematics.

3. Experimental Physics.

4. Chemistry.

5. Botany, including Vegetable Physiology.

6. Zoology.

7. Animal Physiology.

8. Physical Geography and Geology.

9. Logic and Psychology.

"It is intended by the Committee that the examinations in these several subjects should be, as nearly as may be, on the same grade, as to the amount of attainment they require. They have learned from the examiners in mathematics, that their experience justifies them in stating that any candidate who has thoroughly mastered the mathematics of the First B.Sc. Examination, and who has such an aptitude for the study as would lead him to select pure mathematics as one of his subjects at the Second, would find no difficulty in mastering the requirements of its programme, by such an amount of study, carried on through an eight months' academical session, as would leave him free to bestow the same amount of time and attention on two or even three other subjects. And the Committee would wish it to be understood, therefore, that in proposing that each candidate should have his choice of any three out of the nine subjects just specified, the amount of proficiency expected in each would be that which he might attain by the steady devotion to it of about one-third of the sessional work of a diligent student.

"With the further recommendation of the introduction of an efficient practical examination in each of the subjects in which it is feasible, the Committee now place the mature result of their deliberations before the Senate, with considerable confidence that it is the plan most suited to meet the peculiar requirements of the case, and to promote the best interests of scientific education. 